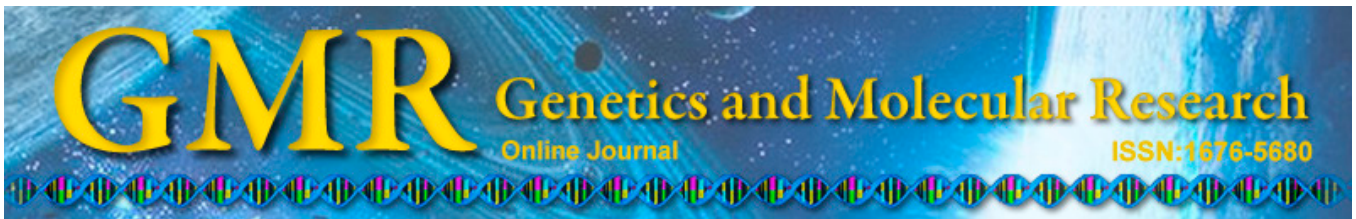

\title{
Expression and significance of SATB1 in the development of breast cancer
}

\author{
S. Zhang, X. Gao, Y. Ma, J. Jiang, Z. Dai, X. Yin, W. Min, W. Hui \\ and B. Wang \\ Oncology of the Second Affiliated Hospital of Xi' an Jiaotong University, \\ Xi'an, China \\ Corresponding author: S. Zhang \\ E-mail: shuqunzhangen@163.com
}

Genet. Mol. Res. 14 (2): 3309-3317 (2015)

Received May 20, 2014

Accepted September 2, 2014

Published April 13, 2015

DOI http://dx.doi.org/10.4238/2015.April.13.10

\begin{abstract}
Special AT-rich sequence binding protein 1 (SATB1) is a recently discovered gene regulator that can promote the growth and metastasis of breast cancer. However, its expression in different stages of breast cancer development have not been examined. We explored the role of SATB1 in the development of breast cancer by detecting SATB1 expression levels in different stages of breast cancer. SATB1 expression was determined using an immunohistochemical streptavidin peroxidase method; the relationship between clinicopathological features of breast cancer and SATB1 expression was analyzed using the $\chi^{2}$ test. Positive rates of SATB1 protein in normal breast tissue, normal breast ductal hyperplasia tissue, precancerous lesions of breast cancer, non-invasive cancer, early invasive carcinoma, and invasive breast cancer tissue were, respectively, 6.25 (2/32), 6.4 (3/47), 20.4 (10/49), $45.0(9 / 20), 52.9(9 / 17)$, and $76.6 \%(72 / 94)$. SATB1 in the latter 3 groups was significantly higher than in the first 3 groups $(\mathrm{P}<$ $0.05)$. The positive rate of SATB1 protein in invasive non-special types of breast cancer $(88.5 \%, 54 / 61)$ was significantly higher than in the special type of invasive breast cancer $(54.5 \%, 18 / 33)$ and early invasive breast cancer $(52.9 \%, 9 / 17)(\mathrm{P}<0.05)$. SATB1 protein expression in
\end{abstract}


breast cancer with lymph node metastasis was generally increased, and the difference was statistically significant $(\mathrm{P}<0.05)$. SATB1 protein expression showed an increasing trend in different stages of breast cancer development. Overexpression indicated poor prognosis.

Key words: Breast cancer; Immunohistochemistry; Special AT-rich sequence binding protein 1

\section{INTRODUCTION}

Breast cancer $(\mathrm{BC})$ is one of the most common malignancies in women, second in cancer mortality in women worldwide, and is increasing each year, making it a serious threat to women's health (Jemal et al., 2009; Friedenreich, 2011). Systemic metastasis is the main cause of death in breast cancer patients and is difficult to treat. Approximately $50 \%$ of patients with breast cancer have had distant metastasis at the first visit to a doctor (Ahmad and Hart, 1997; Parker and Sukumar, 2003). Several gene families have been defined as predictors of tumor progression and recurrence to indicate metastatic potential (Perou et al., 2000; van de Vijver et al., 2002; van't Veer et al., 2002; Ramaswamy et al., 2003). However, the precise molecular mechanisms of breast cancer occurrence and development remain unclear, and thus it is necessary to define molecular markers for early diagnosis and personalized treatment of breast cancer.

Special AT-rich sequence binding protein 1 (SATB1) is a tissue-specific nuclear matrix binding protein that is significantly expressed in thymus cells, progenitor cells, and the basal layer. This protein is expressed at very low levels in normal cells and tissues and is involved in regulating chromatin structure formation and tissue-specific gene expression (Alvarez et al., 2000; Cai et al., 2003; Kohwi-Shigematsu et al., 2012). SATB1 was first identified in $\mathrm{T}$ cells. Under physiological conditions, it plays an important role in T cell development, early red blood cell differentiation, cell homeostasis, and the response to various stimuli (Alvarez et al., 2000; Wen et al., 2005; Cai et al., 2006; Pavan Kumar et al., 2006; Galande et al., 2007). A recent study found that SATB1 is overexpressed in a variety of malignant tumors, such as breast cancer, gastric carcinoma, cutaneous malignant melanoma, larynx, and colorectal cancer, and is an important negative prognostic factor (Han et al., 2008; Cheng et al., 2010; Chen et al., 2011; Zhao et al., 2011; Meng et al., 2012). The SATB1 gene was introduced into non-invasive breast cancer cell lines; these cells acquired invasion and metastasis characteristics. In contrast, silencing of the SATB1 gene in highly invasive breast cancer cell lines can inhibit the tumor growth and metastasis, altering the phenotype of cancer cells to normal cells. SATB1 can regulate the expression of over 1000 genes involved in 61 biological processes, including proliferation, apoptosis, DNA organization, electron transport, protein generation, and receptor activity, indicating that SATB1 is a key molecule in malignant transformation of cells. However, dynamic changes in SATB1 expression during breast cancer development have not been reported.

In this study, we examined the relationship between SATB1 and clinicopathological features of breast cancer and the role of SATB1 in the diagnosis and treatment of breast cancer by detecting the SATB1 protein expression levels in breast cancer tissue at different stages. SATB1 may be a target for the diagnosis and treatment of breast cancer. 


\section{MATERIAL AND METHODS}

\section{Specimen collection}

A total of 259 archived paraffin blocks of breast tissue that had been acquired from patients were collected in the Second Affiliated Hospital of Xi'an Jiaotong University from 2010-2012, of which normal breast tissue was obtained from normal tissue adjacent to breast cancer in 32 patients (median age, 53 years), 47 cases with cystic hyperplasia of breast tissue (median age, 43 years), 49 cases with breast cancer lesions (median age, 44 years), 20 cases with non-invasive cancer (median age, 48 years), 17 cases with early invasive cancer (median age, 55 years), and 94 cases with infiltration breast cancer (median age, 53 years). All cases were confirmed by surgery and pathology; patients were histologically graded based on the Scarff-Bloom-Richardson grading standards and staged with American Joint Committee on Cancer TNM staging.

\section{Materials and methods}

Specimens were fixed with $10 \%$ formalin, embedded with paraffin, and sectioned into $5-\mu \mathrm{m}$ serial sections. A sheet was used for hematoxylin and eosin staining. The immunohistochemical streptavidin-peroxidase (SP) method was applied. Rabbit anti-SATB1 polyclonal antibody (ab49061) was purchased from Abcam (Cambridge, UK) at a 1:100 working concentration. The SP kit was purchased from Beijing Zhongshan Golden Bridge Biotechnology Co., Ltd. Paraffin sections were dewaxed, gradient hydrated, and placed in $10 \mathrm{mM}$ citrate buffer, $\mathrm{pH}$ 6.0. A thermal platform was used to fix the antigen for $3 \mathrm{~min}$, which was then cooled to room temperature. The slice was incubated in 3\% hydrogen peroxide at room temperature for 20 min to eliminate endogenous peroxidase activity. Normal rabbit serum was applied to block the non-specific antigen for $15 \mathrm{~min}$. The excess serum was poured off. The rabbit anti-human polyclonal antibody was added dropwise and then incubated at $4{ }^{\circ} \mathrm{C}$ overnight. After 3-min washes in phosphate-buffered saline 3 times, the biotinylated secondary antibody was added. The slice was incubated at $37^{\circ} \mathrm{C}$ for $30 \mathrm{~min} .3,3^{\prime}$-Diaminobenzidine staining, the hematoxylin resurgence, and neutral resin mounting were analyzed. Breast invasive ductal carcinoma tissue sections were used as the SATB1 positive control. Phosphate-buffered saline (0.01 M, pH 7.4) instead of primary antibody was used as the blank control.

\section{Results criteria}

All biopsy specimens were inspected by 2 experienced pathologists who were blinded to the clinical data. Inconsistencies were resolved through discussion. Four non-repetitive images of each biopsy were observed at least at medium magnification (200X), and the results of SATB1 antibody staining in at least 1000 cells were counted. A light yellow to yellow-brown cytoplasm or nucleus staining in tissue sections was considered a positive cell marker. Expression levels were divided into 3 degrees in accordance with the semi-quantitative method: -, no expression, there was no significant difference in staining intensity and background; +, positive cells $<50 \%$; ++ , strong dyeing, positive cells $>50 \%$, most cells appeared yellow to brownishyellow. 


\section{Statistical methods}

Experimental data were analyzed using SPSS 18.0 (SPSS, Inc., Chicago, IL, USA); statistical analysis was performed using the $\chi^{2}$ test; $\mathrm{P}<0.05$ was considered to be statistically significant.

\section{RESULTS}

In breast cancer, SATB1 was highly expressed in the nucleus and cytoplasm and appeared as brownish-yellow granules; benign breast tissue showed nearly no SATB1 expression. Breast precancerous lesions and noninvasive cancer tissues showed moderate SATB1 expression, while invasive ductal carcinoma showed high SATB1 expression (Figure 1).
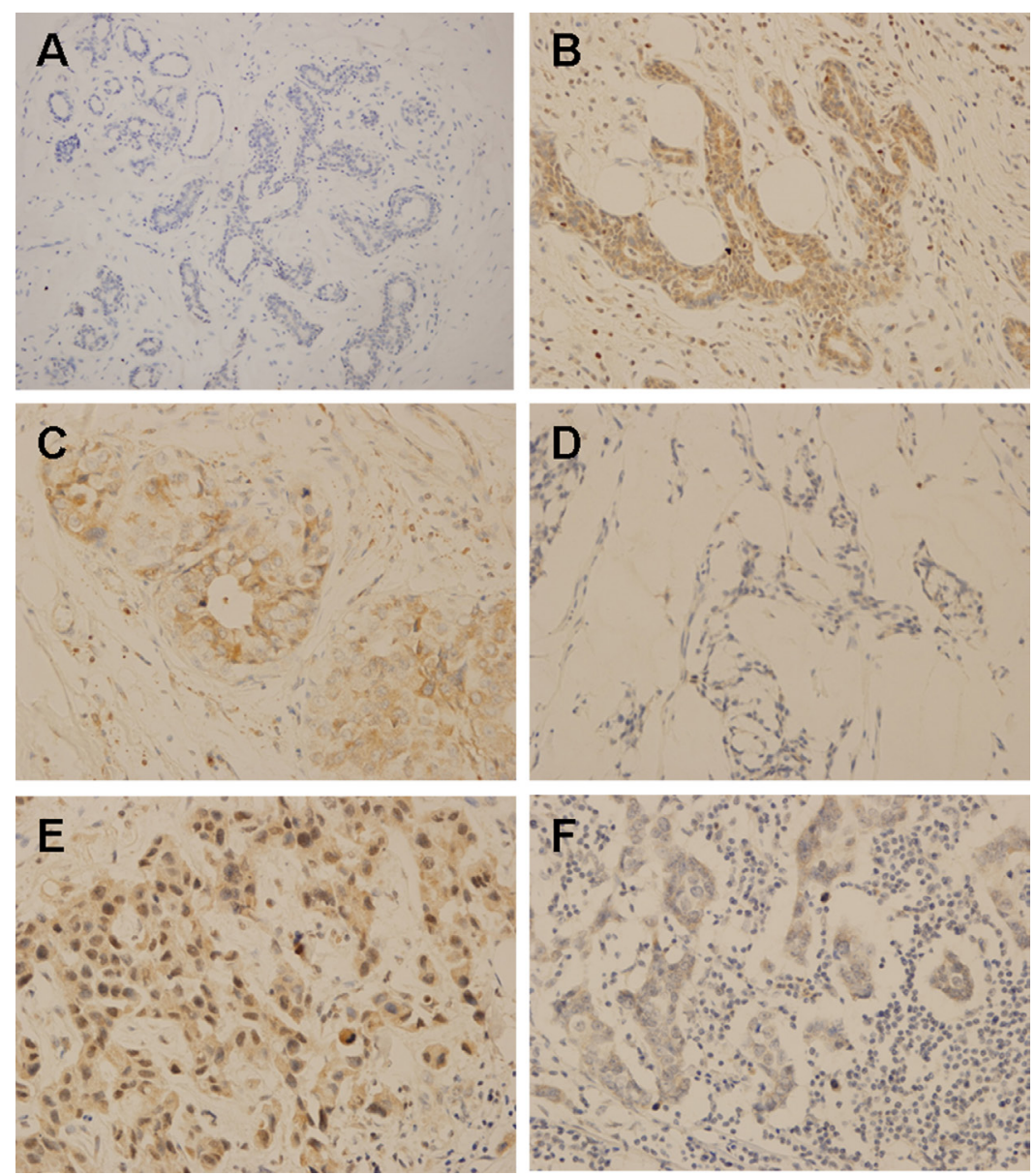

Figure 1. SATB1 expression in breast tissue was detected by immunohistochemical staining (400X): there is no SATB1 expression in the benign breast tissue (-), low expression in breast dysplasia and precancerous lesions (+), high expression in invasive ductal carcinoma $(++)$, weakly positive expression in mucinous carcinoma and medullary carcinoma (+-). A. breast cystic hyperplasia; B. 1 non-special dysplasia of mammary epithelia; C. intraductal carcinoma; D. mucinous carcinoma (rich in cell type); E. invasive ductal carcinom; F. medullary carcinoma. 


\section{Expression of SATB1 in different pathologic types of breast}

The abnormal expression rates of SATB1 in normal breast ductal hyperplasia, precancerous lesions, non-invasive cancer, early invasive carcinoma, and invasive carcinoma groups were, respectively, 6.4, 20.4, 45.0, 52.9, and 76.6\% and showed statistically significant differences $(\mathrm{P}<$ $0.05)$; there was a statistically significant difference in SATB1 abnormal expression rates between the normal breast ductal hyperplasia group (6.4\%) and premalignant lesions group (20.4\%) (P $<0.05)$. There was a statistically significant difference between the premalignant lesions group $(20.4 \%)$ and non-invasive cancer group $(45.0 \%)(\mathrm{P}<0.05)$. There was no statistically significant difference between the non-invasive cancer group $(45.0 \%)$ and early invasive carcinoma group $(52.9 \%)(\mathrm{P}>0.05)$. There was a statistically significant difference between the non-invasive cancer group $(52.9 \%)$ and invasive cancer group $(76.6 \%)(\mathrm{P}<0.01)$. We found that the SATB1 positive expression rate gradually increased during the progression from normal breast tissue, cystic hyperplasia of breast tissue, and precancerous lesions to breast cancer, and the differences were statistically significant, suggesting that SATB1 may be involved in the occurrence, development, and proliferation of breast cancer (Table 1).

\begin{tabular}{|c|c|c|c|c|c|c|}
\hline \multirow[t]{2}{*}{ Groups } & \multicolumn{2}{|c|}{ SATB1 protein expression } & \multirow[t]{2}{*}{ No. of case } & \multirow[t]{2}{*}{ Positive rate } & \multirow[t]{2}{*}{$\chi^{2}$} & \multirow[t]{2}{*}{$P$} \\
\hline & - & +++ & & & & \\
\hline Normal ductal hyperplasia & 44 & 3 & 47 & 6.4 & 78.51 & $<0.01$ \\
\hline Precancerous lesions & 39 & 10 & 49 & 20.4 & & \\
\hline Non-invasive cancer & 11 & 9 & 20 & 45.0 & & \\
\hline Early invasive carcinoma & 8 & 9 & 17 & 52.9 & & \\
\hline Invasive carcinoma & 22 & 72 & 94 & 76.6 & & \\
\hline Total & 124 & 103 & 227 & 45.4 & & \\
\hline
\end{tabular}

\section{SATB1 expression in different invasive types of breast cancer}

The SATB1 positive expression rates in non-special invasive breast cancer (invasive ductal carcinoma/invasive lobular carcinoma), medullary carcinoma (typical medullary carcinoma), mucinous carcinoma, and other special types of invasive cancer were, respectively, $80.8 \%(63 / 78), 66.7 \%(4 / 6), 25 \%(1 / 4)$, and $66.7 \%(4 / 6)$. There was a statistically significant difference in SATB1 abnormal positive expression rate between the non-special invasive type of cancer group and medullary carcinoma group $(\mathrm{P}<0.05)$; there was a statistically significant difference between the special type invasive carcinoma group and mucinous carcinoma group $(\mathrm{P}<0.05)$. Our experiment showed that SATB1 had lower positive expression with a better prognosis of the pathologic types of breast cancer, suggesting that SATB1 may be associated with poor prognosis of breast cancer as reported by Han et al. (2008) (Table 2).

Table 2. Expression of SATB1 in the different types of breast cancer.

\begin{tabular}{lrrrr}
\hline Groups & \multicolumn{3}{c}{ SATB1 protein expression } & \multirow{2}{*}{ No. of case } \\
\cline { 2 - 5 } & - & + & ++ & 43 \\
Special type of invasive cancer & 15 & 20 & 0 & 78 \\
Medullary carcinoma & 2 & 4 & 0 & 6 \\
Mucinous carcinoma & 3 & 3 & 1 & 6 \\
Other special type of invasive cancer & 2 & 3 & \\
\hline
\end{tabular}




\section{Relationship between SATB1 expression and clinicopathological parameters}

The positive expression rate of SATB1 showed no significant relationship with patients' age, tumor size, or estrogen and progesterone status $(\mathrm{P}>0.05)$, but was possibly related to her-2 $(\mathrm{P}=0.054)$. The abnormal positive expression rates significantly differed by pathological type and clinical TNM stage $(\mathrm{P}<0.05)$ (Table 3$)$. Additionally, the high expression of SATB1 was related to axillary lymph node metastasis $(\mathrm{P}<0.05)$.

Table 3. Association between SATB1 expression and the pathologically biological behavior of breast carcinoma.

\begin{tabular}{|c|c|c|c|c|c|c|}
\hline \multirow[t]{2}{*}{ Variables } & \multicolumn{3}{|c|}{ SATB1 expression } & \multirow[t]{2}{*}{ Total } & \multirow[t]{2}{*}{ Percent (\%) } & \multirow[t]{2}{*}{$\mathrm{P}$} \\
\hline & - & + & ++ & & & \\
\hline \multicolumn{7}{|l|}{ Age (years) } \\
\hline$\leq 50$ & 16 & 15 & 21 & 52 & 69.2 & \multirow{2}{*}{0.706} \\
\hline$>50$ & 14 & 19 & 26 & 59 & 76.3 & \\
\hline \multicolumn{7}{|l|}{ Tumor size } \\
\hline$\leq 2 \mathrm{~cm}$ & 11 & 12 & 9 & 32 & 65.6 & \multirow[t]{2}{*}{0.154} \\
\hline$>2 \mathrm{~cm}$ & 19 & 22 & 38 & 79 & 75.9 & \\
\hline \multicolumn{7}{|l|}{ Histology } \\
\hline Early infiltrating breast cancer & 8 & 6 & 3 & 17 & 52.9 & \multirow[t]{3}{*}{0.004} \\
\hline Infiltrating special breast cancer & 7 & 7 & 2 & 16 & 56.3 & \\
\hline Infiltrating non-special breast cancer & 15 & 21 & 42 & 78 & 80.8 & \\
\hline \multicolumn{7}{|l|}{ Clinical stage } \\
\hline I, II & 27 & 25 & 30 & 82 & 67.1 & \multirow[t]{2}{*}{0.039} \\
\hline III & 3 & 9 & 17 & 29 & 89.7 & \\
\hline \multicolumn{7}{|l|}{ Lymph node metastasis } \\
\hline Negative & 26 & 25 & 28 & 79 & 67.1 & \multirow[t]{2}{*}{0.035} \\
\hline Positive & 4 & 9 & 19 & 32 & 87.5 & \\
\hline \multicolumn{7}{|l|}{ Estrogen receptor } \\
\hline Positive & 21 & 18 & 24 & 63 & 66.7 & \multirow[t]{2}{*}{0.227} \\
\hline Negative & 9 & 16 & 23 & 48 & 81.2 & \\
\hline \multicolumn{7}{|l|}{ Progesterone receptor } \\
\hline Positive & 12 & 14 & 19 & 47 & 70.2 & \multirow[t]{2}{*}{0.342} \\
\hline Negative & 8 & 20 & 26 & 54 & 85.2 & \\
\hline \multicolumn{7}{|l|}{ Her-2 } \\
\hline$-/+$ & 28 & 29 & 34 & 91 & 67.0 & \multirow[t]{2}{*}{0.054} \\
\hline$++/+++$ & 2 & 5 & 13 & 20 & 90.0 & \\
\hline
\end{tabular}

\section{DISCUSSION}

SATB1 was screened by Dickinson et al. in 1992 using the gene enhancer 3 Mars sequence as a probe in the $\mathrm{L}$ chain of the immunoglobulin heavy chain from a human cDNA library. SATB1 is located on the third chromosome (3p23) in humans and has a total length of 763 amino acids. The protein has a unique cage-like structure that anchors to chromatin to facilitate the activity of numerous transcription factors. Thus, it plays an important role in gene transcription (Cai et al., 2003). A previous study found that SATB1 was highly expressed in breast cancer tissue and showed nearly no expression in normal controls. SATB1 can transform some non-malignant mammary epithelial cell lines into malignant cells. However, SATB1 silencing in the breast cancer cells MDA-MB-231 with invasion and metastasis characteristics can alter the invasion phenotype and inhibit tumor growth, suggesting that this gene plays a key role in tumorigenesis and cancer development (Han et al., 2008; Cheng et al., 2010; Chen et al., 2011; Zhao et al., 2011; Meng et al., 2012; Ordinario et al., 2012). Genomics research found that SATB1 can affect the expression of more than 1000 genes involved in 
tumorigenesis, increase the expression of promoting transfer genes, and reduce the expression of metastasis suppressor genes. Multivariate analysis of SATB1 and prognosis of breast cancer revealed that SATB1 expression was independent of other prognostic factors (including tumor stage, histological grade, and lymph node involvement status) and was an independent prognostic factor for breast cancer (Han et al., 2008).

SATB1 was found to be more highly expressed in invasive and drug-resistant breast cancer cell lines than in the non-resistant parental cell lines. Some of the multidrug-resistant phenotype was reversed when the level of SATB1 was reduced. Previous studies suggested that SATB1 mediates the resistance of tumor cells by inhibiting tumor cell apoptosis (Li et al., 2010). Another study found that chemotherapy can reduce the level of microRNA-448. SATB1 levels increased when microRNA-448 was inhibited, causing an epithelial-mesenchymal transition and leading to malignant progression ( $\mathrm{Li}$ et al., 2011). SATB1 can regulate the expression of more than 1000 genes, which can affect tumor markers (including HER2/neu, matrix metalloprotease 2, Abelson murine leukemia viral oncogene homolog 1, E-cadherin). SATB1 expression was found to be positively correlated to a variety of biological and genetic markers (including CyclinD1, matrix metalloprotease 2, nuclear factor-kappaB, and proliferating cell nuclear antigen), and was related to nearly absent expression of adenomatous polyposis coli and BRAF (V600E) (Mir et al., 2012; Zhang et al., 2013). Thus, it may be the key factor in malignant cell development. However, few studies have examined the relationship between SATB1 and malignant tumors. In this study, an immunohistochemical SP assay was applied to detect SATB1 expression in 131 cases with invasive breast cancer tissue. The results showed that SATB1 expression was positive in 90 breast cancer specimens $(68.7 \%)$, while the SATB1 positive rate was only $6.25 \%$ in adjacent normal glands, which is consistent with the results of previous studies. In addition, because of the multi-step and progressive characters of breast cancer, we examined SATB1 expression at different stages of breast cancer development and found that in the progression from normal breast tissue, cystic hyperplasia of breast tissue, breast precancer lesions to breast cancer, and the positive rate of SATB1 gradually increased. Statistical analysis revealed that SATB1 expression in breast cancer patients $(68.7 \%)$ was significantly higher than in the normal breast ductal hyperplasia group (6.4\%), suggesting that SATB1 may be involved in breast tissue development, progression, and proliferation to cancer. Compared with the non-invasive cancer group $(45.0 \%)$ and non-specific invasive cancer group $(80.8 \%)$, SATB1 expression showed a statistically significant difference $(\mathrm{P}<0.01)$. Expression in the axillary lymph node-positive group was significantly higher than in the negative group, suggesting that high expression played an important role in breast cancer invasion and lymph node metastasis. The positive expression rate of SATB1 in a better prognosis of medullary carcinoma of the breast was $66.7 \%$, which was lower than in the more invasive non-specific cancer type $(80.5 \%)$. The difference was statistically significant $(\mathrm{P}<0.05)$. Charpin et al. (1999) suggested that medullary cancer cells had relatively high E-cadherin expression level, which may limit the growth and spread of the tumor and may be a factor in medullary carcinoma fit growth and good prognosis. Han et al. (2008) and other studies have found that SATB1 knockout increased E-cadherin expression and decreased fibronectin and E-cadherin inhibitory factors (SNAIL and SIP1), suggesting that SATB1 may affect the evolution and prognosis of the tumor by regulating the expression of E-cadherin. Thus, SATB1 is expected to be a reliable indicator of the development and prognosis of breast cancer, and can be used to comprehensively confirm the malignant degree and invasive and metastatic potentiality of breast cancer, providing a basis for individualized treatment. 
SATB1 can alter the gene expression profile to quickly change the cell phenotype. SATB1 can regulate and change the type and function of many cells. However, the mechanism of SATB1 must be further examined. The study confirmed that the SATB1 level increased in breast cancer and other tumor cells was increased compared to in normal tissue, and can regulate the development and metastasis of tumor. Thus, SATB1 it is an important prognostic marker. The mechanism of increased SATB1, the signaling pathway involved in the development of the tumor, and the role of this protein in regulating signal transductions have not been thoroughly examined. Some studies reported that Foxp3 microRNAs can regulate the SATB1 expression level (Beyer et al., 2011; Li et al., 2011; Lena et al., 2012; McInnes et al., 2012; Yang et al., 2012), and some post-translational modifications with biological significance have been identified (Pavan Kumar et al., 2006; Purbey et al., 2009). Another study found that the ataxia telangiectasia mutated protein can inhibit SATB1-induced malignant progression of mammary epithelial cells (Ordinario et al., 2012). SATB1 can also be recognized by CD8+, suggesting that SATB1 can be used for tumor immunotherapy (Wang et al., 2013).

SATB1 may become a new gene target for cancer treatment. It is necessary to further examine the mechanism how SATB1 regulates the development of malignant tumors.

\section{REFERENCES}

Ahmad A and Hart IR (1997). Mechanisms of metastasis. Crit. Rev. Oncol. Hematol. 26: 163-173.

Alvarez JD, Yasui DH, Niida H, Joh T, et al. (2000). The MAR-binding protein SATB1 orchestrates temporal and spatial expression of multiple genes during T-cell development. Genes Dev. 14: 521-535.

Beyer M, Thabet Y, Müller RU, Sadlon T, et al. (2011). Repression of the genome organizer SATB1 in regulatory T cells is required for suppressive function and inhibition of effector differentiation. Nat. Immunol. 12: 898-907.

Cai S, Han HJ and Kohwi-Shigematsu T (2003). Tissue-specific nuclear architecture and gene expression regulated by SATB1. Nat. Genet. 34: 42-51.

Cai S, Lee CC and Kohwi-Shigematsu T (2006). SATB1 packages densely looped, transcriptionally active chromatin for coordinated expression of cytokine genes. Nat. Genet. 38: 1278-1288.

Charpin C, Bonnier P, Garcia S, Andrac L, et al. (1999). E-cadherin and beta-catenin expression in breast medullary carcinomas. Int. J. Oncol. 15: 285-292.

Chen H, Takahara M, Oba J, Xie L, et al. (2011). Clinicopathologic and prognostic significance of SATB1 in cutaneous malignant melanoma. J. Dermatol. Sci. 64: 39-44.

Cheng C, Lu X, Wang G, Zheng L, et al. (2010). Expression of SATB1 and heparanase in gastric cancer and its relationship to clinicopathologic features. APMIS 118: 855-863.

Dickinson LA, Joh T, Kohwi Y and Kohwi-Shigematsu T (1992). A tissue-specific MAR/SAR DNA-binding protein with unusual binding site recognition. Cell 70: 631-645.

Friedenreich CM (2011). Physical activity and breast cancer: review of the epidemiologic evidence and biologic mechanisms. Recent Results Cancer Res. 188: 125-139.

Galande S, Purbey PK, Notani D and Kumar PP (2007). The third dimension of gene regulation: organization of dynamic chromatin loopscape by SATB1. Curr. Opin. Genet. Dev. 17: 408-414.

Han HJ, Russo J, Kohwi Y and Kohwi-Shigematsu T (2008). SATB1 reprogrammes gene expression to promote breast tumour growth and metastasis. Nature 452: 187-193.

Jemal A, Siegel R, Ward E, Hao Y, et al. (2009). Cancer statistics, 2009. CA Cancer J. Clin. 59: 225-249.

Kohwi-Shigematsu T, Poterlowicz K, Ordinario E, Han HJ, et al. (2012). Genome organizing function of SATB1 in tumor progression. Semin. Cancer Biol. 23:72-79.

Lena AM, Mancini M, Rivetti di Val Cervo P, Saintigny G, et al. (2012). MicroRNA-191 triggers keratinocytes senescence by SATB1 and CDK6 downregulation. Biochem. Biophys. Res. Commun. 423: 509-514.

Li QQ, Chen ZQ, Xu JD, Cao XX, et al. (2010). Overexpression and involvement of special AT-rich sequence binding protein 1 in multidrug resistance in human breast carcinoma cells. Cancer Sci. 101: 80-86.

Li QQ, Chen ZQ, Cao XX, Xu JD, et al. (2011). Involvement of NF- $\kappa$ B/miR-448 regulatory feedback loop in chemotherapyinduced epithelial- mesenchymal transition of breast cancer cells. Cell Death Differ. 18: 16-25. 
McInnes N, Sadlon TJ, Brown CY, Pederson S, et al. (2012). FOXP3 and FOXP3-regulated microRNAs suppress SATB1 in breast cancer cells. Oncogene 31: 1045-1054.

Meng WJ, Yan H, Zhou B, Zhang W, et al. (2012). Correlation of SATB1 overexpression with the progression of human rectal cancer. Int. J. Colorectal Dis. 27: 143-150.

Mir R, Pradhan SJ and Galande S (2012). Chromatin organizer SATB1 as a novel molecular target for cancer therapy. Curr. Drug Targets 13: 1603-1615.

Ordinario E, Han HJ, Furuta S, Heiser LM, et al. (2012). ATM suppresses SATB1-induced malignant progression in breast epithelial cells. PLoS One 7: e51786.

Parker B and Sukumar S (2003). Distant metastasis in breast cancer: molecular mechanisms and therapeutic targets. Cancer Biol. Ther. 2: 14-21.

Pavan Kumar P, Purbey PK, Sinha CK, Notani D, et al. (2006). Phosphorylation of SATB1, a global gene regulator, acts as a molecular switch regulating its transcriptional activity in vivo. Mol. Cell 22: 231-243.

Perou CM, Sørlie T, Eisen MB, van de Rijn M, et al. (2000). Molecular portraits of human breast tumours. Nature 406: 747-752.

Purbey PK, Singh S, Notani D, Kumar PP, et al. (2009). Acetylation dependent interaction of SATB1 and CtBP1 mediates transcriptional repression by SATB1. Mol. Cell. Biol. 29: 1321-1337.

Ramaswamy S, Ross KN, Lander ES and Golub TR (2003). A molecular signature of metastasis in primary solid tumors. Nat. Genet. 33: 49-54.

van de Vijver MJ, He YD, van't Veer LJ, Dai H, et al. (2002). A gene-expression signature as a predictor of survival in breast cancer. N Engl. J. Med. 347: 1999-2009.

van't Veer LJ, Dai H, van de Vijver MJ, He YD, et al. (2002). Gene expression profiling predicts clinical outcome of breast cancer. Nature 415: 530-536.

Wang M, Yin B, Matsueda S, Deng L, et al. (2013). Identification of special AT-rich sequence binding protein 1 as a novel tumor antigen recognized by CD8(+) T cells: implication for cancer immunotherapy. PLoS One 8: e56730.

Wen J, Huang S, Rogers H, Dickinson LA, et al. (2005). SATB1 family protein expressed during early erythroid differentiation modifies globin gene expression. Blood 105: 3330-3339.

Yang S, Banerjee S, Freitas A, Cui H, et al. (2012). miR-21 regulates chronic hypoxia-induced pulmonary vascular remodeling. Am. J. Physiol. Lung Cell. Mol. Physiol. 302: L521-L529.

Zhang J, Zhang B, Zhang X, Sun Y, et al. (2013). SATB1 expression is associated with biologic behavior in colorectal carcinoma in vitro and in vivo. PLoS One 8: e47902.

Zhao XD, Ji WY, Zhang W, He LX, et al. (2011). Overexpression of SATB1 in laryngeal squamous cell carcinoma. ORL J. Otorhinolaryngol. Relat. Spec. 72: 1-5. 